DOI: http://dx.doi.org/10.20435/1148

\title{
Destinação dos resíduos sólidos como sustentabilidade no meio rural
}

Allocation of solid waste as sustainability in rural areas

\author{
Ludmila Saldanha Escobar ${ }^{1}$ \\ Eloir Trindade Vasques Vieira ${ }^{2}$ \\ Luís Carlos Vinhas Ítavo ${ }^{3}$ \\ José Aparecido Moura Aranha ${ }^{4}$
}

${ }^{1}$ Pós-graduanda em Gestão em Agronegócio pela UCDB/Portal Educação (lato sensu). E-mail: ludy-escobar@hotmail.com

${ }^{2}$ Doutora em Ciências Ambientais e Sustentabilidade Agropecuária, Mestre em Desenvolvimento Local e graduada em Ciências Contábeis. Coordenadora e professora do curso de graduação em Ciências Contábeis da Universidade Católica Dom Bosco (UCDB). E-mail: eloir@ucdb.br

${ }^{3}$ Doutor em Zootecnia, mestre em Zootecnia e graduação em Zootecnia. Professor Adjunto na Faculdade de Medicina Veterinária e Zootecnia (FAMEZ) da Universidade Federal de Mato Grosso do Sul (UFMS).E-mail: luis.itavo@ufms.br

${ }^{4}$ Doutor em Ciências Ambientais e Sustentabilidade Agropecuária, Mestre em Ciências Contábeis, graduado em Ciências Contábeis e em Administração. Professor Adjunto na Escola de Administração e Negócios (ESAN) da Universidade Federal de Mato Grosso do Sul (UFMS). E-mail: jaranha@terra.com.br 


\section{RESUMO ABSTRACT}

Trata-se de artigo de revisão bibliográfica acerca da produção e destinação de resíduos sólidos em áreas rurais. Sabe-se

que os resíduos são motivo de grande preocupação na atualidade, de forma que seu descarte de maneira incorreta acarreta sérios danos ao meio ambiente. 0 trabalho parte dos conceitos de gestão ambiental para, em seguida, abordar sobre meio ambiente e sustentabilidade e, posteriormente discute resíduos sólidos no meio rural. Conclui-se que as melhores formas de descarte de resíduos no meio rural são a compostagem de materiais orgânicos, reciclagem e reutilização e aterramento do lixo cujo reúso não é possível.

PALAVRAS-CHAVE

desenvolvimento sustentável gestão ambiental meio ambiente
This is a literature review article about the production and disposal of solid waste in rural areas. It is known that the waste is of great concern today, so that its disposal incorrectly causes serious damage to the environment. The leave work of environmental management concepts and then approaches on environment and sustainability, and later discussed solid waste in rural areas. We conclude that the best forms of waste disposal in rural areas are the composting of organic materials, recycling and reuse and waste ground that reuse is not possible.

\section{KEY WORDS}

sustainable development

environmental management

environment 


\section{INTRODUÇÃo}

Na atualidade a produção de resíduos sólidos é cada vez em grande escala e há uma grande preocupação no que diz respeito ao uso e desuso adequado deles. No meio rural, não é diferente. As populações que vivem em áreas rurais sobrevivem não só da agropecuária, mas também de outras atividades. Seja qual for a forma de subsistência, o lixo no meio rural é algo mais preocupante, pois as propriedades, por estarem geralmente afastadas do meio urbano, e acaba sendo descartado de forma irregular e danosa ao meio ambiente. Toda propriedade rural, sendo de grande ou pequeno porte, pode encontrar maneiras mais sustentáveis de manejo no que se refere ao lixo produzido.

Diante disso, há a preocupação em que se possa avaliar a dimensão da produção desses resíduos sólidos nas áreas rurais, descobrir as principais formas de descarte usadas pelos produtores rurais e, por fim, principalmente propor formas mais adequadas de descarte do lixo a serem utilizadas nessas propriedades. Formas essas que estejam de acordo com a realidade do local e que estejam em conformidade com a gestão ambiental e a sustentabilidade.

Dessa forma, com a preocupação que vivemos hoje em relação à preservação do meio ambiente e com as formas de diminuir os impactos sobre este, a questão do descarte adequado dos resíduos sólidos em áreas rurais se torna um tema de suma importância, já que os produtores rurais vêm cada vez mais se inserindo, de forma significativa, na economia das comunidades, inclusive urbanas.

O objetivo da pesquisa é fazer uma abordagem exploratória sobre o descarte de resíduos sólidos no meio rural bem como apontar procedimentos mais adequados para esses descartes. A pesquisa, quanto à metodologia, caracteriza-se como qualitativa, o tipo adotado foi exploratório descritivo e, quanto aos procedimentos, trata-se de pesquisa bibliográfica. 


\section{A GESTÃo AMBIENTAL}

A Gestão Ambiental vem se tornando uma formação de importância no que diz respeito ao meio ambiente, sustentabilidade e também no âmbito social, já que o meio ambiente é formado também de pessoas que saibam com ele conviver em harmonia.

A importância da área foi destacada inclusive como uma das profissões do futuro, já que cada vez mais o ser humano vem necessitando de formas e alternativas que venham ao encontro da preservação ambiental e da harmonia entre natureza e o homem. Os estudos de impacto ambiental na atualidade são imprescindíveis tanto em grandes obras de infraestrutura, como a extração de recursos minerais e o agronegócio, atividades essas que são coordenadas pelo profissional da área da Gestão Ambiental, bem como precisam saber o custo econômico, social e ambiental.

Segundo Donaire (1999, p. 20), a responsabilidade social implica uma forma de obrigação para com a sociedade, assumindo assim diversas formas, "entre as quais se incluem proteção ambiental, projetos educacionais, serviços sociais em conformidade com o interesse público".

A Gestão Ambiental envolve diversas premissas, sendo necessário um conjunto de ações sobre políticas públicas, os setores da produção e a comunidade e sociedade em geral, incentivando o uso adequado e racional dos recursos ambientais. Compreende-se que a responsabilidade social está intimamente ligada à preservação da vida em um todo, requerendo uma atenção à qualidade de vida da população, comunidade e também de gerações futuras.

Segundo Quintas (2006), não é possível que haja em uma sociedade democrática a Gestão Ambiental sem a participação em conjunto do Estado e sociedade civil.

Dessa forma, faz-se necessário apresentar ações em comum e objetivos compartilhados. 


\subsection{Gestão ambiental empresarial}

Atualmente as empresas são as grandes causadoras da maior degradação do meio ambiente, devendo assim buscar maneiras de ao menos minimizar esses danos. Os gestores devem passar a considerar o meio ambiente em sua tomada de decisões e adotar concepções que contribuam para ampliar a capacidade de suporte do planeta (BARBIERI, 2007).

0 gerenciamento eficaz dos resíduos sólidos dessas empresas, podem contribuir muito para que os danos ambientais se tornem menos significativos à natureza. Sugere-se a percepção de todos os envolvidos sobre a importância do assunto, já que não existem fórmulas prontas nem métodos garantidos para se obter sucesso na Gestão Ambiental.

Dentre as várias formas de se gerir ambientalmente, a política dos 3 R's, como é conhecida, se torna uma solução que se pode ser aplicada tanto nas empresas como em nossas próprias casas, já que isso significa nada mais que Reduzir, Reutilizar e Reciclar. Reduzindo e reutilizando, podemos evitar que maiores quantidades de produtos se transformem em lixo. E reciclando, podemos prolongar a utilidade dos recursos naturais e também reduzir o volume desses resíduos sólidos (BONELLI, 2010).

Reduzir o lixo em nossas casas e empresas implica evitar tudo que não nos é realmente necessário. Isso significa preferir embalagens de papel e papelão que são recicláveis e não poluem, rejeitando as de plástico, por exemplo.

Para Bonelli (2010), reutilizar significa usar um mesmo produto de várias maneiras, como por exemplo utilizar embalagens de plástico ou vidro para plantar ou até mesmo fazer brinquedos, ou reutilizar folhas de papel usadas para blocos de anotações. Sobre a reciclagem, o autor Bonelli (2010) ainda diz que é uma forma de lidar com o lixo de forma a reduzir e reusar o que antes não teria serventia. Esse processo consiste basicamente em fazer 
coisas novas a partir de coisas usadas, contribuindo para reduzir o volume de lixo, diminuir a poluição e a contaminação, assim como também economiza os materiais e energia usados na fabricação de outros produtos.

Os princípios de sustentabilidade da política dos 3 R's surgem como alternativas fáceis de serem adotadas, sendo possível que cada indivíduo possa contribuir para uma gestão mais adequada à preservação do meio ambiente. Seguindo essa premissa, podemos citar Henares (2006, p. 45), que confere aos resíduos sólidos um ciclo de vida a cumprir, o que implica sua valorização na cadeia produtiva da reutilização e reciclagem, chamando à responsabilidade o poder público, a sociedade civil e o setor empresarial.

Segundo o Instituto Brasileiro do Meio Ambiente e dos Recursos Naturais Renováveis (IBAMA, 2011), reciclagem e artesanato trazem benefícios na questão ambiental, econômico e social, já que ambos contribuem para a diminuição da pressão antrópica sobre os recursos naturais e também aumento da renda familiar.

Nesse sentido, é cada vez mais necessária a preocupação e reflexão, disseminação proposição de ideias e práticas que tornem realidade a sustentabilidade ambiental, aliando crescimento econômico, preservação do meio ambiente e equidade social. Dentre os benefícios de ter sucesso ao aliar essas ideias, está o fato de que essas empresas ganham um olhar positivo das demais instituições, dando bom exemplo a ser continuado e seguido e também gerando oportunidade de novos negócios.

\subsection{Sustentabilidade}

Outra vertente de grande importância quando se fala de Gestão Ambiental é a sustentabilidade, que tem ganhado destaque devido à crescente conscientização da necessidade de melhoria nas condições ambientais, econômicas e sociais, de forma a aumentar qualidade de vida de toda a sociedade, preservando o 
meio ambiente, assim como ter organizações sustentáveis econômicas e indivíduos socialmente sustentáveis. Assim, uma gestão ambientalmente correta tem como princípio a sustentabilidade, em todas as suas esferas. Mais que os benefícios à sociedade, a adoção de mecanismos sustentáveis tem sido estrategicamente pensada como uma forma de diferenciação de produtos e também para inserção em alguns mercados. Sobre isso, Buainain (2006, p. 47), apresenta a seguinte opinião:

[...] uma vez que busca garantir que a satisfação das necessidades de hoje não pode comprometer o meio ambiente e criar dificuldades para as gerações futuras. Nesse sentido, a ideia de desenvolvimento sustentável carrega um forte conteúdo ambiental e um apelo claro à preservação e à recuperação dos ecossistemas e dos recursos naturais.

Dessa forma, conforme afirma o autor, quando se fala em sustentabilidade, automaticamente se associa a causa ambiental, já que um grande dano ao meio ambiente pode trazer efeitos negativos irreparáveis não só ao local de origem como também a áreas mais distantes, já que os ecossistemas se interligam na natureza. 0 termo sustentabilidade vai muito além de não degradar o meio ambiente, pode-se associar a ele várias outras questões como qualidade de vida, sucesso e competitividade empresarial, tecnologias limpas e corretas, responsabilidade social entre outros.

Diante disso, pode-se dizer que o termo sustentabilidade vai além somente da causa ambiental. Para os autores Barbieri e Cajazeira (2009), as dimensões da sustentabilidade são várias: social, econômica, ecológica, espacial, cultural, política e institucional. Assim, procurar soluções para viver de forma sustentável pode melhorar a qualidade de vida dos indivíduos em todas as suas formas, seja no dia a dia com sua comunidade como também na área econômica, já que aplicar formas sustentáveis pode trazer redução de gastos, melhorando assim a questão econômica familiar. Pelo fato de a percepção sobre a utilização dos recursos 
naturais e o desenvolvimento econômico e social ser muito pessoal, a sustentabilidade não possui um conceito definitivo, apesar de cada vez mais ser utilizada em diversos setores da economia. Não há uma definição única, porém há direcionamentos comuns entre os diversos autores e até organizações envolvidas com a temática, permitindo entender os fatores que devem ser considerados ao se avaliar a sustentabilidade de um sistema ou organização.

Ainda segundo Barbieri e Cajazeira (2009), ao resumirem as dimensões da sustentabilidade, chamam de sustentabilidade ecológica aquela relacionada ao meio ambiente, e que se refere às ações para evitar danos ao meio ambiente, causados pelos processos de desenvolvimento, como por exemplo a redução de poluentes e utilização de recursos renováveis, além da preservação da biodiversidade.

De acordo com Araújo et al. (2006), a sustentabilidade pode ser dividida em três dimensões principais: ambiental, econômica e social, de forma que, para uma empresa ou organização ser considerada sustentável, é preciso ter sucesso, ações efetivas e criteriosas nessas três áreas.

Em seu sentido lógico, a sustentabilidade é a capacidade de se autossustentar, de se manter. É como se uma atividade sustentável fosse algo que pudesse durar para sempre, sempre se renovando, não se esgotando nunca.

Uma sociedade sustentável é aquela que não coloca em risco os elementos do meio ambiente, com ele convivendo de forma harmônica. 0 desenvolvimento sustentável, tão falado nos dias atuais, é a alternativa capaz de melhorar a qualidade de vida do homem na Terra, ao mesmo tempo em que respeita a capacidade de produção dos ecossistemas em que vivemos.

Conforme interpretação de Scharf (2004), o desenvolvimento sustentável tem como objetivo a preservação da riqueza global, que, segundo seu entendimento, refere-se aos ativos financeiros, recursos naturais e também à qualidade de vida da população. 
Esse conceito leva em conta também sentimentos como de solidariedade e preocupação com as gerações futuras, já que um ambiente malcuidado hoje, trará consequências graves no futuro, limitando a possibilidade que temos hoje de atender as próprias necessidade através da natureza.

Segundo Almeida (2002), a maior dificuldade encontrada atualmente não é elaborar o conceito de desenvolvimento sustentável, mas sim colocá-lo em prática.

Evidencia-se que a grande maioria das pessoas sabe bem sobre a fase ruim que se encontra a questão ambiental, sabe de todas as consequências que o mau uso dos recursos naturais podem trazer, principalmente para as gerações futuras. Entretanto muito se fala e pouco se faz.

\section{RESÍDUOS SÓLIDOS}

Os resíduos sólidos constituem uma preocupação mundial principalmente no âmbito ambiental, de forma que se não forem descartados de forma correta provocam efeitos diretos e indiretos na saúde das comunidades e ainda mais ao meio ambiente, já que esses resíduos possuem materiais e substâncias que podem pôr em risco o ambiente onde foram dispensados (GRANZIERA, 2009).

A questão do lixo torna-se um grave problema socioambiental, já que está intimamente ligada à saúde pública, por fazer parte do saneamento básico, e, nos países subdesenvolvidos, isso se torna ainda mais preocupante, pois a população desses locais carece de informações e orientações adequadas para a gestão do lixo produzido. A Associação Brasileira de Normas Técnicas (ABNT), por meio da norma NBR n. 10.004, define os resíduos sólidos como sendo:

Resíduos nos estados sólido e semi-sólido, que resultam de atividades da comunidade de origem: industrial, doméstica, hospitalar, comercial, agrícola, de serviços de variação. Ficam incluídos nesta 
definição os lodos provenientes de sistema de tratamento de água, aqueles gerados em equipamentos e instalações de controle de poluição, bem como determinados líquidos cujas particularidades tornem inviável seu lançamento na rede pública de esgotos em corpos d'água, [...]. (ABNT, 2004, p. 1).

Como se observa, os resíduos sólidos possuem diferentes estados de forma física e também de procedência. Porém, qualquer que seja sua origem, todos causam danos ao meio ambiente, seja em maior ou menor grau. Surge dessa preocupação, a importância de encontrar meios de descarte que possam ser postos em prática no presente, nos dias atuais.

Quanto os resíduos sólidos industriais, estes possuem em sua maioria um número elevado de substâncias tóxicas e materiais perigosos que necessitam tratamento especial (TOCCHETTO, 2009), tanto pela produção em larga escala quanto pelos componentes químicos que geralmente essas indústrias usam em suas atividades.

Ainda segundo a NBR 10.004 (ABNT, 1987), os resíduos sólidos industriais possuem sua classificação em:

Perigosos/Classe 1: Resíduos que podem apresentar riscos à saúde pública e ao meio ambiente, devido suas propriedades químicas e infecto-contagiosas. Podem possuir características como inflamabilidade, corrosividade, reatividade, toxidade e patogenicidade.

Não Inertes/Classe 2: São os resíduos que não se enquadram na Classe 1 ou 3, podem apresentar propriedades como combustibilidade, biodegrabilidade, e solubilidade em água. São dessa forma considerados os menos nocivos.

Inertes/Classe 3: Pode ser quaisquer resíduos que submetidos a um contato estático ou dinâmico com água, não tenham nenhum de seus componentes solubilizados a concentrações superiores aos padrões de potabilidade de água.

Esses resíduos sólidos industriais são, muitas vezes, recolhidos pelos serviços municipais de limpeza urbana, tendo muitas vezes o mesmo destino final que os resíduos sólidos urbanos, quando não contratam empresas privadas especializadas em 
coletas industriais. 0 manejo adequado desses resíduos é uma importante estratégia de preservação do meio ambiente, assim como de promoção e proteção da saúde em geral. A decomposição da matéria orgânica do lixo resulta em um líquido escuro e altamente contaminante, chamado de chorume. Ele pode contaminar o solo e as águas superficiais ou subterrâneas, já que pode alcançar os lençóis freáticos. Podem formar gases tóxicos e explosivos que se acumulam no subsolo ou muitas vezes são lançados à atmosfera, causando grandes prejuízos ao meio ambiente e à saúde dos seres vivos.

Além de todos esses impactos imediatos, os resíduos sólidos contribuem de maneira significativa com o processo de mudanças climáticas, ou o que chamamos de aquecimento global. Sobre isso, John et al. (2000, p. 15) tem a seguinte opinião:

De fato, os resíduos se transformaram em graves problemas urbanos e ambientais com um gerenciamento oneroso e complexo. A escassez de área de deposição de resíduos causada pela ocupação e valorização de áreas urbanas, os altos custos sociais no gerenciamento de resíduos, problemas de saneamento público e contaminação ambiental são alguns destes problemas.

De acordo com a opinião do autor e como já foi destacado, os resíduos sólidos podem ser considerados um grave problema da atualidade, que pode trazer consequências em todos os âmbitos da sociedade, tanto no social, econômico e principalmente para a área ambiental.

Uma solução simples para o destino do lixo orgânico é a compostagem, algo que todos podem adotar em suas residências. Além dos aspectos benéficos, como a eliminação da contaminação ambiental, o produto final obtido é um fertilizante natural de alta qualidade. Observa-se que a destinação correta desses resíduos sólidos e, por consequência, a diminuição dos impactos ambientais causados pelo lixo dependem de um conjunto de fatores que é obrigação de todos. 
Segundo Bidone e Teixeira (1999), a definição de uma solução para o gerenciamento geral desses resíduos deve ser maleável, já que se deve levar em conta a complexidade da relação entre geração de resíduos e alteração nos hábitos de vida das populações. A educação ambiental volta a ser apontada como parte da solução, sendo preciso integrá-la de forma responsável na construção de medidas técnica e ambientalmente corretas.

Dessa forma, no senso comum, pode se concluir que é como se fosse uma escala de tarefas, na qual todos os envolvidos precisam fazer a sua parte para se ter sucesso em busca de um objetivo comum.

\section{4 ÁREA RURAL}

A importância da área rural em todo o mundo sempre foi evidenciada, e é preciso que todos saibam que a vida em geral depende do meio rural para sobreviver, já que a grande maioria dos produtos alimentícios necessários à subsistência do ser humano advém das áreas rurais. São fazendas, sítios, chácaras e assentamentos que plantam, colhem, criam animais e cultivam tanto para seu próprio consumo, quanto para a renda familiar, levando sua produção até os centros urbanos.

De acordo com Barbosa (2005), o meio rural não é mais um espaço onde são desenvolvidas atividades exclusivamente agrícolas. Esse meio tem passado por intensas mudanças, que induzem à pluralidade, fazendo com que o espaço seja tido como uma continuação da zona urbana.

Os habitantes do campo possuem hábitos bem peculiares de vida e também no que diz respeito ao descarte do lixo, já que a grande maioria foi acostumada, desde a infância, a jogar esses resíduos a margem dos rios, nos quintais de suas casas, em buracos cavados para esse fim ou ainda os incinerando. 
Segundo dados do Instituto Brasileiro de Geografia e Estatística (IBGE, 2000), o trabalho de coleta do lixo na área rural e em áreas mais afastadas dos centros urbanos ainda é insuficiente, o que leva esses moradores a descartar seu lixo em locais inadequados, pois além de não contar com coleta municipal, muitas vezes são áreas bem afastadas, onde as pessoas não têm acesso à cidade com facilidade para poder levar seu lixo. Percebe-se assim a grande dificuldade em destinar adequadamente o lixo que se produz nas propriedades rurais e, principalmente, destiná-lo da forma correta para uma melhor preservação ambiental e também melhor condição de vida aos que moram na propriedade.

Percebe-se que há uma preocupação das propriedades rurais com a questão ambiental, entretanto a conscientização dos moradores é muito difícil. Os proprietários e principalmente funcionários rurais possuem em sua maioria baixa escolaridade e difícil acesso à informação, dificultando assim a conscientização de forma mais satisfatória.

De acordo com Darolt (2002), o lixo rural é composto principalmente por restos vegetais da cultura e materiais associados à produção agrícola (adubos químicos, defensivos e suas embalagens, dejetos animais, produtos veterinários...) quanto por resíduos semelhantes aos produzidos nas cidades (restos de alimentos, vidros, latas, papéis, plásticos, pilhas, lâmpadas, baterias e etc.).

Outra grande preocupação no que diz respeito ao lixo das áreas rurais está no uso indiscriminado de agrotóxicos e fertilizantes químicos, que, além de produzirem lixo com suas embalagens, também causam grandes danos aos animais, às plantas, às águas e ao próprio homem.

Nessa condição, pode-se chegar a um patamar de insustentabilidade em que tal avanço tecnológico necessita ser repensado de maneira crítica para garantir inclusive sua própria manutenção como mediador das relações entre sociedade e natureza. Cada propriedade rural pode possuir diversos tipos de lixos, já que a produção depende muito do tipo de cultura praticada no 
local. Por exemplo, a criação de porcos, ou suinocultura, produz grandes quantidades de dejetos como fezes e restos de alimentos que, em contato com o solo ou rios, podem causar graves danos ambientais. Por outro lado, esses dejetos, se adequadamente manejados, podem resultar em benefícios para a propriedade, como créditos de carbono, geração de energia elétrica pela queima do gás metano resultante da fermentação anaeróbia e biofertilizante. A venda de créditos de carbono e a redução na conta de energia elétrica têm reflexos na renda da propriedade, e a irrigação com o biofertilizante, além de proporcionar melhores colheitas, melhora as condições físicas e químicas do solo irrigado. Entretanto, para isso se fazem necessários investimentos.

Uma das formas de descarte bastante utilizada, tanto no meio rural como urbano, é o aterramento sanitário, por ser uma forma barata, porém depende de um local adequado, para que não ocorra contaminação na superfície nem no lençol freático. Esse método consiste em dispor o lixo em camadas intercaladas com terra, sendo prensados por máquinas em um local escavado. Lima e Cavalheiro (1993) citam que o aterramento sanitário possui inúmeras vantagens, entre elas capacidade de absorção diária de grande quantidade de resíduos, condições especiais para a decomposição de matéria orgânica, limitação da procriação de vetores prejudiciais ao homem entre outros.

Evidencia-se ainda que muitas propriedades também utilizam a incineração desse lixo, por ser uma forma rápida e fácil de descarte, porém uma forma inadequada, já que a queima desses resíduos pode trazer fumaça tóxica ao meio ambiente.

Autores reforçam que essas formas de descarte se mostram eficientes e sustentáveis na área rural, porém todas possuem sua parcela de agressão à natureza, de uma forma ou de outra. 0 mais indicado então, é escolher a forma mais adequada à realidade de determinada propriedade, reduzindo ao mínimo possível os danos ao meio ambiente. 


\section{CONCLUSÃo}

Para viver de forma sustentável ambientalmente, busca-se um processo lento a longo prazo, que envolve conscientização e educação ambiental para as gerações futuras.

Outro grande desafio a ser enfrentado é a real implementação de políticas públicas ambientais que promovam efetivamente o desenvolvimento sustentável. Para que o desenvolvimento sustentável seja efetivo realmente, é preciso que a natureza seja entendida como parte integrante do processo de produção e, principalmente, como finita.

Faz-se necessário observar que sustentabilidade não significa somente a conservação dos recursos naturais, mas também planejamento territorial tanto das áreas urbanas como rurais, gerenciamento dos recursos naturais, controle e estímulo às práticas culturais, à saúde, alimentação e, sobretudo, à qualidade de vida. A sustentabilidade deve ser aplicada às comunidades, sendo organizadas de modo que seus estilos de vida, atividades econômicas e tecnologias não prejudiquem a capacidade da natureza em sustentar a vida. Uma comunidade com esse princípio de sustentabilidade é o primeiro passo para um futuro de mais harmonia entre ser humano e meio ambiente.

Evidencia-se que grande parcela da sociedade, principalmente as dos países ricos, vive em uma época de consumismo desenfreado, no qual produtos eletrônicos, por exemplo, são cada vez mais substituídos rapidamente, resultando em uma proporção gigantesca do chamado "lixo eletrônico", um dos problemas mundiais da atualidade. $\mathrm{Na}$ área rural, a preocupação com o descarte de produtos também se faz necessária, porém, em outro nível, pois várias atividades, tais como a suinocultura, pode ocasionar danos ao solo, principalmente se próximo a rios, ou lagos. Não se podem descartar os danos que o lixo rural causa ao meio ambiente, pois cada vez mais essas áreas vêm fazendo parte da vida, inclusive de comunidades urbanas. 
Os problemas que o descarte inadequado de todo esse lixo pode trazer são muito maiores e mais preocupantes do que investir em soluções para minimizar esses impactos, é nesse cenário que entra o profissional capacitado para propor formas ambientalmente sustentáveis, uma vez que não é possível eliminar por completo a produção de resíduos sólidos; deve-se, portanto, encontrar maneiras de diminuir seus impactos, de forma a agredir o meio ambiente o mínimo possível.

Toda área que se localiza no meio rural, seja ela de grande ou pequeno porte, pode encontrar formas mais corretas e sustentáveis de manejo do lixo produzido. Dessa forma, pode-se concluir que as melhores formas de descarte de resíduos no meio rural são a compostagem de materiais orgânicos, reciclagem e reutilização e aterramento do lixo que não passível de reúso. É preciso cada vez mais conscientização, muita informação e educação ambiental nessas propriedades. 0 processo é em longo prazo, já que envolve transformações estruturais e também culturais.

Faz se necessário, colocar em prática todos os conhecimentos que se tem, mesmo que seja fazendo pouco, no dia a dia, nas residências. Essas ações acabam se tornando grandes se cada um fizer a sua parte em busca de um futuro melhor, vivendo o hoje com mais sustentabilidade. Vale ressaltar que o problema do lixo rural ainda é pouco discutido e estudado, o que se sugere o mínimo de recursos para a busca de estratégias que minimizem o problema.

Por fim, é de fundamental importância encontrar equilíbrio entre a produção da propriedade rural e a preservação ambiental. Assim a sugestão é, cada vez mais através de estudos de casos, encontrar soluções mitigadoras para a coleta e armazenagem no interior das propriedades, utilizando meios mais adequados e com o mínimo de impacto ambiental. 


\section{REFERÊNCIAS}

ASSOCIAÇÃO BRASILEIRA DE NORMAS TÉCNICAS (ABNT). NBR 10.004; Resíduos Sólidos - Classificação. Rio de Janeiro, 1987.

ALMEIDA, R. O bom negócio da sustentabilidade. 1. ed. Rio de Janeiro: Nova Fronteira, 2002.

ARAÚJO, G. C. et al. Sustentabilidade empresarial: conceitos e indicadores. In: CONGRESSO BRASILEIRO VIRTUAL DE ADMINISTRAÇÃO, 3., 2006. Disponível em: <http://www.convibra.com.br/2006/artigos/61_pdf. pdf>. Acesso em: 17 jul. 2016.

BARBIERI, J. C. Gestão ambiental empresarial: conceitos, modelos e instrumentos. 2. ed. atual. e ampl. São Paulo: Saraiva, 2007.

BARBIERI, J. C.; CAJAZEIRA, J. E. R. Responsabilidade social empresarial e empresa sustentável: da teoria à prática. São Paulo: Saraiva, 2009.

BARBOSA, G. L. M. Gerenciamento de resíduo sólido: Assentamento Sumaré II, Sumaré- SP. 2005. 147f. Dissertação (Mestrado em Saneamento e Ambiente) - Faculdade de Engenharia Civil, Arquitetura e Urbanismo, UNICAMP, Campinas, SP, 2005.

BIDONE, F. R. A.; TEIXEIRA, E. N. Metodologia e técnicas de minimização, reciclagem e reutilização de resíduos sólidos urbanos. Rio de Janeiro: ABES, 1999.

BONELLI, C. M. C. Meio ambiente, poluição e reciclagem. 2. ed. São Paulo: Blucher, 2010.

BUAINAIN, A. M. Agricultura familiar, agroecologia e desenvolvimento sustentável: questões para debate. Brasília: IICA, 2006.

DAROLT, M. R. Lixo rural: entraves, estratégias e oportunidades. Planeta Orgânico, Ponta Grossa, 2002. Disponível em: <http://www. planetaorganico.com.br/trabalhos.htm>. Acesso em: 10 ago. 2016.

DONAIRE, D. Gestão ambiental nas empresas. 2. ed. São Paulo: Atlas, 1999.

GRANZIERA, M. L. M. Direito ambiental. São Paulo: Atlas, 2009.

HENARES, E. L. Educação ambiental e resíduos sólidos: a ação da COOPERLIX em Presidente Prudente-SP. 2006. Dissertação (Mestrado 
em Geografia) - Faculdade de Ciências e Tecnologia, Universidade Estadual Paulista, Presidente Prudente, SP, 2006.

INSTITUTO BRASILEIRO DE GEOGRAFIA E ESTATÍSTICA (IBGE). Censo Demográfico de 2000. Rio de Janeiro, 2000. Disponível em: <http:// www.ibge.gov.br>. Acesso em: 10 jul. 2016.

INSTITUTO BRASILEIRO DO MEIO AMBIENTE E DOS RECURSOS NATURAIS RENOVÁVEIS (IBAMA). Mudanças climáticas globais, queimadas e incêndios florestais. Cartilha publicada pelo Ministério do Meio Ambiente, 2011.

JOHN, V. M; ANGULO, S. C; AGOPYAN, V. Sobre a necessidade de metodologia de pesquisa e desenvolvimento para reciclagem. São Paulo: PCC - Departamento Engenharia de Construção Civil da Escola Politécnica/EP USP, 2000.

LIMA, M. A.; CAVALHEIRO, F. Análise da degradação ambiental do município de Rio Claro com o apoio do sistema de informações geográficas. In: SIMPÓSIO BRASILEIRO DE SENSORIAMENTO REMOTO, 7. Anais... Curitiba, 1993. p.83-91

QUINTAS, J. S. Introdução à gestão ambiental pública. 2. ed. rev. Brasília: IBAMA, 2006. 134p. (Coleção Meio Ambiente. Série Educação ambiental, $5)$.

SCHARF, R. Manual de negócios sustentáveis. São Paulo: Amigos da Terra - Amazônia Brasileira; Fundação Getúlio Vargas, Centro de Estudos em Sustentabilidade, 2004.

TOCCHETTO, M. R. L. Gerenciamento de resíduos sólidos industriais. Universidade Federal de Goiás. Curso de Especialização em Tratamento e Disposição Final de Resíduos Sólidos e Líquidos, 2009. 